\title{
Meta
}

Journal des traducteurs

Translators' Journal

\section{Accountability in Translation Within and Beyond the Sentence as the Key Functional UT: Three Case Studies}

\section{Chunshen Zhu}

Volume 50, numéro 1, mars 2005

Enseignement de la traduction dans le monde

Teaching Translation Throughout the World

URI : https://id.erudit.org/iderudit/010676ar

DOI : https://doi.org/10.7202/010676ar

Aller au sommaire du numéro

Éditeur(s)

Les Presses de l'Université de Montréal

ISSN

0026-0452 (imprimé)

1492-1421 (numérique)

Découvrir la revue

Citer cet article

Zhu, C. (2005). Accountability in Translation Within and Beyond the Sentence as the Key Functional UT: Three Case Studies. Meta, 50(1), 312-335.

https://doi.org/10.7202/010676ar
Résumé de l'article

L'article fait suite à une étude antérieure (Zhu 1999). Trois traductions de l'anglais vers le chinois sont analysées pour valider le cadre théorique proposé. On cherche successivement à voir : 1) le lien qui existe entre le mode de présentation linéaire de l'information à l'intérieur de la phrase et le potentiel textuel de celle-ci ; 2) la relation entre telle structure thématique de la phrase et sa fonction dans le texte ; 3 ) la nécessité et la possibilité d'aligner, par une articulation appropriée de la syntaxe, l'acte de discours dans la phrase avec celui du texte. Les trois études de cas sur lesquelles repose l'analyse ne sont pas indépendantes, comme on pourrait le croire à première vue : elles sont reliées et présentées suivant une progression. Cet article vise à remplacer la seconde partie d'une étude précédente (Zhu 1996a).
Ce document est protégé par la loi sur le droit d'auteur. L'utilisation des services d’Érudit (y compris la reproduction) est assujettie à sa politique d'utilisation que vous pouvez consulter en ligne.

https://apropos.erudit.org/fr/usagers/politique-dutilisation/ 


\title{
Accountability in Translation Within and Beyond the Sentence as the Key Functional UT: Three Case Studies
}

\author{
CHUNSHEN ZHU \\ City University of Hong Kong, Kowloon, Hong Kong \\ ctzhu@cityu.edu.hk
}

\begin{abstract}
RÉSUMÉ
L'article fait suite à une étude antérieure (Zhu 1999). Trois traductions de l'anglais vers le chinois sont analysées pour valider le cadre théorique proposé. On cherche successivement à voir: 1) le lien qui existe entre le mode de présentation linéaire de l'information à l'intérieur de la phrase et le potentiel textuel de celle-ci; 2) la relation entre telle structure thématique de la phrase et sa fonction dans le texte; 3) la nécessité et la possibilité d'aligner, par une articulation appropriée de la syntaxe, l'acte de discours dans la phrase avec celui du texte. Les trois études de cas sur lesquelles repose l'analyse ne sont pas indépendantes, comme on pourrait le croire à première vue: elles sont reliées et présentées suivant une progression. Cet article vise à remplacer la seconde partie d'une étude précédente (Zhu 1996a).
\end{abstract}

\begin{abstract}
The article is a sequel to Zhu (1999). It provides three case studies of translation from English into Chinese, which are designed to substantiate the theoretical framework established therein. It discusses the relationship between a sentence's internal linear mode of information presentation and its textual potential, the relationship between a sentence's thematic structure and its functional status in the text, and the necessity and possibility to align sentential speech acts with the textual speech act through appropriate syntactic management. The three case studies, independent as they may seem, are correlated and have been arranged in a progressive order. This article is intended to replace the second part of Zhu (1996a).
\end{abstract}

\section{MOTS-CLÉS/KEYWORDS}

unit of translation, textual integrity, textuality, speech act sequence, information presentation

\section{Introduction}

In translation teaching or practice, more often than not one has to have recourse to analyses of individual sentences, either in isolation or in context, in order to produce plausible description or assessment of a translational operation. In such analyses sentences in question are treated technically as Units of Translation (UTs). In applying the notion of UT to the study of translation, the development of text linguistics and discourse analysis in the last few decades, however, has posed serious challenges to traditional sentence-centred, grammatically-oriented approaches. At the same time it offers possibilities to advance the study of sentences for translation purposes on a more analytical and less speculative basis, by alerting translation teachers, as well as theorists and practitioners, to the relationship between the formation of the 
sentence and its function in the formulation of the text as the end product of translating process.

Elsewhere (Zhu 1999, replacing the first part of Zhu 1996a), I have proposed a threefold conception of the functions of the UT, based on the seven elements of textuality, namely:

(1) the function of syntactic bearer: it has to be grammatically appropriate in order to provide a material basis for textual cohesion and coherence;

(2) the function of information carrier: it has to convey ideationally and interperpersonally significant messages (coherence) so as to render the text informative and relevant (informativity and relevance);

(3) the function of stylistic marker: it has to contribute to textual organization by means of judicious paradigmatic choice of words and syntagmatic choice of word-order; so its mode of information presentation can serve the textual intention more purposefully (intentionality), and the text's genre membership and textual individuality (intertextuality) can be more effectively accepted (acceptability).

It has also been argued that these functions constitute the textual integrity of a UT (with the sentence as the key functional UT) to be realized in a target text; and that in translating a text, without the respect for the textual integrity of a UT, textuality will become groundless, and without the authority of textuality (of the whole text), textual integrity on any lower level will become unhinged. In either case the construction of a target text as a coherent Structure of Meaning is in jeopardy.

The argument serves as the theoretical framework for the present case studies, which have been arranged in a progressive order, altogether to illustrate the relationship between thematic structure, speech act sequence and textual integrity at both intra- and inter-sentential levels. The discussion will concern itself with the following three aspects:

(1) the relation between a sentence's internal mode of information presentation and its potential textual integrity in target textualization;

(2) the importance of a target-language sentence's thematic structure in preserving its textual integrity in relation to the whole target text; and

(3) the necessity to align sentential speech acts with the textual speech act through appropriate syntactic management.

In this study, sentential grammaticality is taken as the prerequisite for the function of syntactic bearer so as to focus our attention on a sentence's textual potential, and on how a textual awareness in translating can help narrow down selections on the one hand and prompt more effective solutions on the other.

\section{Case One as a Starter: Sequence, process, and effect}

Let us look at the following sentence:

[1]

[Ed Thatcher was a little man with two blond wisps of mustache and washed out gray eyes.] He seized the nurse's hand and shook it showing all his uneven yellow teeth in a smile.

(John Dos Passos: Manhattan Transfer) 
with a proposed Chinese translation:

[1. tr]

他一把抓住護士的手搖著, 露出滿口不整齊的黃牙微笑著。

[Back-translation] He seized the nurse's hand shaking it, showed all his uneven yellow teeth smiling.

Elsewhere (Zhu 1996b) I have observed the possibility, as demonstrated in this translation, of keeping to the source-text's sequence of information presentation even though its syntactic pattern has to be altered with the promotion of the showingphrase from a modifier to the status of predicate. Here we concentrate on the choice of words and word order that enables the sentence's function as information carrier and stylistic marker. According to Leech and Short, the stylistic features and effects created by the process of information presentation in this sentence are:

a. that 'the aggressive connotations of seize, shook, and uneven teeth' nearly 'trick the reader into a wholly negative response';

b. that the smile is delayed to the end, to defeat the reader's expectation of 'a snarl rather than a smile; ; and

c. that the connection between the handshaking and the smile is forced by juxtaposition and reinforced by alliteration: "shook ... showing".

(Leech and Short 1981:240-241)

Obviously, most cognitive information is carried by words with independent content meaning (denotation), i.e., content words. Within the sentence, these words, firstly as information carriers, are intended to give the sentence its locutionary sense after they have taken their syntactic positions. (Auxiliary sub-carriers are those function words suggesting, for example, logical relations between content words.) Secondly, in order to account for the illocutionary intention of inviting a 'negative response,' the word seize, which contributes to the sentence's stylistic-marking as well as information-carrying function, has to be viewed against its semantic field membership, ranging from a neutral take to a metaphorical claw, so as to get to its right connotations of abruptness and unexpectedness with a touch of crudity, which are packed in the Chinese translation into the phrase 一把抓住 ('take hold with one grasp'). By the same token, 滿口 ('full-mouth') has been added to account for the tone that has been 'played up' by the all in the original, as 不整齊的黄牙 ('uneven yellow teeth') may not sound as aggressive as its source-text counterpart. Yet one has to be careful not to overdo the image of yellow teeth, although it could be tempting to do so by, say, picking up the ready-made phrase 大黃牙 ('big yellow teeth'), as the phrase may give an impression too pejorative to be redeemed by the smile at the end of the sentence. With a matching aggressive connotation maintained in those key words, efforts have also been made to delay the 微笑著 ('smiling') to the end, in a similar attempt to defeat the target reader's expectation of a 'snarl.' As for the sound effect achieved through the choice of shook and showing with a stylistic marking implication, we have to give up the reinforcing alliteration as its effect is source language-bound. In its place, however, there is an echoing pair of 搖著 ('shaking') and 微笑著 ('smiling'), the compensatory sound effect of which has been enhanced by the target-text's more neatly paralleled formation.

If a translation aims solely at the conveyance of the source text's factual content, a great variety of versions can be viable candidates so long as they contain a similar 
chunk of factual information. This is where paraphrase finds its place. For instance, simply by regrouping the four actions in [1] above, i.e., seizing, shaking, showing and smiling, within the contour of the sentence itself (which is grammatically possible in both English and Chinese), we would be able to turn out a number of variations, let alone by paraphrasing at the word level. Thus in translating, and particularly in literary translating, while gauging the information to be carried into the target text, we have to be on the lookout for stylistic marks, for something unique to the source text that is conducive to the textual effect perceived by the translator, as further determinants to narrow down choices available in the target language to a functionally assessable extent. The function of stylistic marking, as we have demonstrated, can be performed subtly and effectively by syntagmatic choice of the linear sequence (in this case the delaying of the smile) as well as paradigmatic choice of words. All this has to be observed primarily at the sentence and confirmed eventually at the text level. In this way the notion of the sentence as the key functional UT will not be misconstrued to be allowance for random or even wanton re-grouping of information elements within a sentence, which could lead a translator to nowhere but 'free' (in the sense of 'disorganized') translation. Instead, in this research, we try to observe how a targettext sentence, as prompted by the source text, can be syntactically managed to bear up a flow of information structured to be more effectively perceived and accepted by the reader in line with the overall communicative purpose of the text.

It has to be pointed out, though, that with the sentence assessed and translated out of its context, what we have retrieved is but its potential textual integrity. A sentence's textual potential as such can be established as its realized textual integrity only when the sentence joins and contributes to the formulation of the text.

\section{Case Two: Between a sentence and the text}

\subsection{A semantic-thematic analysis of the source text's syntactic sequence}

When a sentence enters textualization, interrelations between its function-based textual integrity and that of its co-text contribute substantially to the text's coherence, and has to be closely observed in translating as well as writing. In translating as a source-text induced type of writing, to maintain such interrelations demands a lot of careful attention, especially those marked by thematic structural manipulation rather than overt cohesive clues (see Halliday 1985:sec.9.6 for the structural as well as cohesive features of text formulation). If we find that the thematic structure in a sentence has contributed to the SL textualization, then we will expect its counterpart to do the same in the target text with a matching (though not necessarily identical) deployment of its componential units accountable for the creation of the intended effects. This, again, calls for close observation of the intra-sentential structure, as we can see in the following discussion of the beginning of Jane Austen's Pride and Prejudice, probably one of the most studied sentences in English literature, and its translating into Chinese:

[2]

It is a truth universally acknowledged, that a single man in possession of a good fortune, must be in want of a wife. 
It has been widely recognized that the sentence's syntactic arrangement renders it subtle with interpersonal meaning. On the one hand a philological analysis of the sentence's punctuation provided by Nash (1992:51-53) has helped us better appreciate the delicacy of the sentence's 'dimension of feeling.' On the other hand a violation of the Gricean Maxims of Quality (i.e., Do not say that for which you lack adequate evidence or what you believe to be false.) and Quantity (i.e., Make your contribution to the conversation just as informative as is required.) in the sentence's wording points to an implicature of irony, as signalled by the over-modifying of the truth with the universally acknowledged (see Leech and Short 1981:303, and Carter 1987:195196, for their respective analyses of the sentence). Apart from this, the delivery of such attitudinal information, whether it is one of inaccessible delicacy or of specific irony, has been enhanced by the sentence's mode of linguistic formulation of the information. This is achieved firstly through syntactic cohesion marked by the parallel and antithetical structure in possession of ... in want of, secondly through lexical cohesion between possession and fortune, and thirdly through language-specific phonological cohesion of the alliterative in want of a wife. A comparison with:

[2. i]

It is a truth universally acknowledged, that a wealthy single man must need a wife

will highlight the role of these cohesive devices in rendering [2] textually effective. They help sustain the sentence not only as a bearer of sound grammaticality and a carrier of a message similar to that delivered by [2. i], but also as a stylistic marker that 'sets the tone for the rest of the novel' (Leech and Short 1981:303) in a way different from any other possible versions.

There is, however, one more important feature of the sentence's syntactic pattern, i.e., its sequential arrangement of information, made possible by English grammar, which facilitates its stylistic marking function as the opening of the whole story. That is, by postponing the that-clause the sentence not only adopts a more natural rightbranching pattern, ${ }^{1}$ but also creates a suspense: the reader's curiosity may be aroused by that high-sounding, or 'lexico-syntactic "overloading"' (Carter 1987:196), proclamation of 'a universally acknowledged truth.' With the proclamation as the 'given' information, the sentence proceeds to give the content of the 'truth' as the 'new' information, which the reader is expected by the author to refute or keep distance from (by a rhetorical means of bathos in its propositional content, as noted by Chang 1996:126; so far as register is concerned, to be sure, the language still maintains a tone suggestive of pomposity). In terms of linguistic formulation at this sentential level, the real-time perception of the informational sequence in [2] progresses in a way similar to:

[2. ii]

A truth universally acknowledged (Theme/Given) // is that a single man in possession of a good fortune must be in want of a wife (Rheme/New).

This represents an open-ended, or outwards-tracking as Nash (1980:114) would describe it, distribution of speech acts, i.e., ASSERTION + ENUNCIATION, which will interpersonally accentuate readers' interest by posing a mock challenge to their belief in life. In term of information structure, admittedly, the indefinite article $a$ in 'a truth' indicates the entity is new to the text. Actually, since this is the beginning of the 
whole novel, the whole sentence can be taken as containing new information. But within the sentence itself, the 'theme' part is 'given' as the starting point for the progression of information presentation. With the entity 'a truth' being fronted in the It is ... that ... pattern, the ideational element of the clausal rheme must be in want of a wife is left in the end-focus position and can be regarded as the focal information of the sentence. This perception is congruent with the development of the story as a whole. Compare:

[2. iii]

That a single man in possession of a good fortune must be in want of a wife (Theme/ Given) // is a truth universally acknowledged (Rheme/New)

in which the syntax is head-weighted and the information structure is close-ended in terms of speech act sequencing, bordering on something like OBSERVATION + CONCLUSION. ${ }^{2}$ As a result, interpersonally [2. iii] tends to invite a response more of disagreement about the (mockingly) asserted 'universal acknowledgement' of the 'truth,' rather than one of curiosity induced by a disagreement about the need of a wealthy man for a wife; thus textually, such an opening would look sliced-off from the rest of the novel.

Following the information sequence as observed in [2. ii], on a lower, i.e., phrasal or clausal level, [2] can be further parsed to reveal more minute informational designs.

Firstly, the Theme/Given part of the sentence, i.e., It is a truth universally acknowledged, contains a post-modifying structure, which, in terms of sequence, is similar to theme-rheme or given-new information presentation: 'a truth // universally acknowledged,' in which the universally as a modifier foregrounds the modified acknowledged by indicating the supposed spatial prevalence of the 'acknowledgement' (for the foregrounding function of a modifier, see Zhu 1996b); while the seemingly pure grammatical device of It is, in 'its simple present tense,' suggests the supposed temporal permanence of the 'truth,' as well as textually bearing the sentential status of the line and syntactically preparing the reader for a that-clause to come. It is worth noting that the concept of 'truth', as the given element, is supposed to be extra-textually retrievable from the reader's pre-existent conceptual system to start off the perception of the information. And in a translational context, readers from different language backgrounds may come up with different modes of conceptualization of truth.

For instance, a 'truth' for an English reader can mean 'a fact, idea, or principle that is generally accepted to be true' (Collins COBUILD English Language Dictionary 1987, italics added). Hence, according to Carter (1987:196), 'if a truth is a truth it does not need to be "universally acknowledged"; and the relation that sustains this phrasal theme-rheme-like post-modification is not a process of providing conceptual new information but one of 'lexico-syntactic “overloading”' In Chinese however, 真理, the lexical counterpart of truth given by English-Chinese dictionaries, is a certain 'correct reflection' of the objective world on human consciousness (cf. 《現代漢語辭典》 'A Modern Chinese Dictionary,' 1996). Thus for a Chinese reader, or for one who sees a 'truth' in a Chinese light, the term as it stands seems to have more to do with 'correctness' than with 'acceptance' or 'acknowledgement'; and consequently, the postmodification in the phrase can appear to be a process of providing new information 
about the extent of the purported truth's being acknowledged, or, as [2. tr.i] below suggests, even about a state of 'gaining ground.'

Secondly, the sentential rheme, the that-clause, can be further divided into the clausal theme a single man in possession of a good fortune and the clausal rheme must be in want of a wife; where the clausal theme is sustained by a similar post-modification relation: 'a single man // in possession of a good fortune.' The modalized clause, by playing upon the primary and secondary functions of must (relating respectively to 'duty' and 'almost certainty,' see Alexander 1988:207-208), suggests a kind of selfassumed truthfulness of the 'truth.'

Our analysis so far has led to the following linear segmentation of the thematic structure as linguistically formulated in [2]:

FIGURE 1

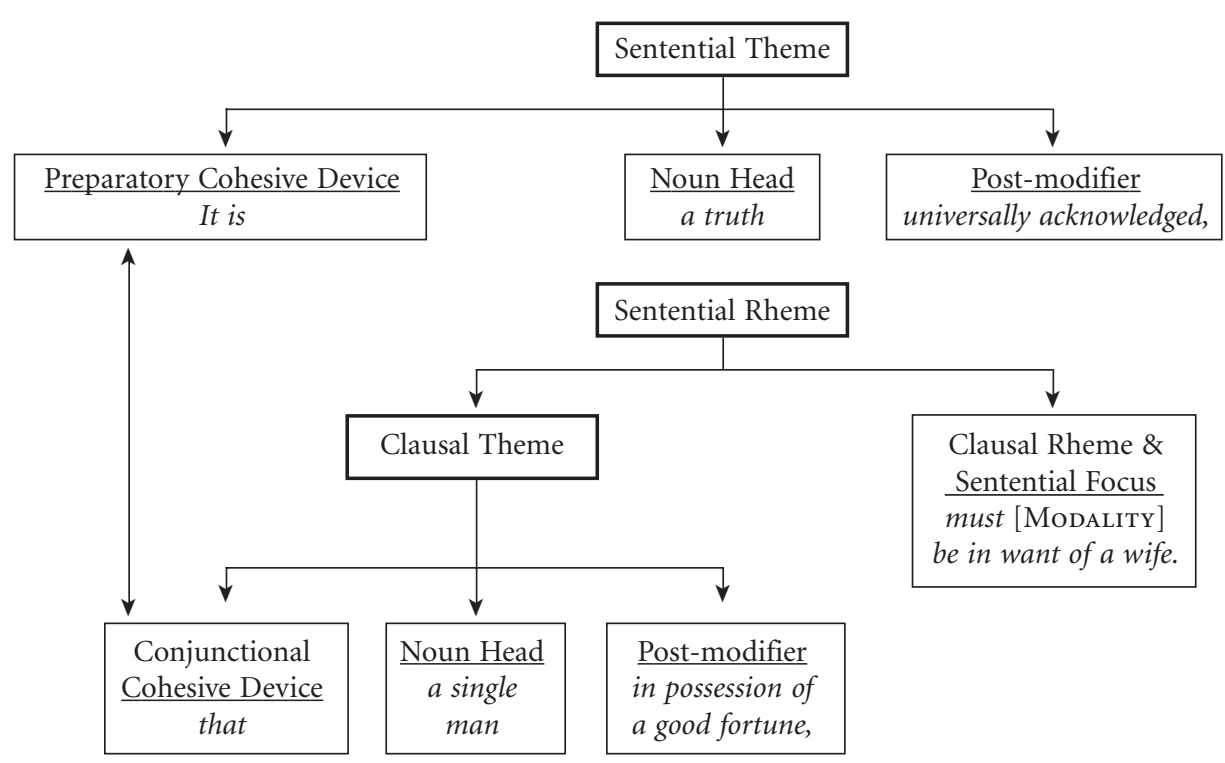

Or:

It is (Preparatory Cohesive Device) a truth (Noun Head) / universally acknowledged (Post-modifier) \{Sentential Theme\} /// that (Conjunctional Cohesive Device responding to the previous cohesive device) a single man (Noun Head) / in possession of a good fortune (Post-modifier) [Clausal Theme] // must (MODALITY) be in want of a wife [Clausal Rheme \& Sentential Focus] \{Sentential Rheme\}.

Given the fact that in an unmarked information structure, theme is within the given and the new information is within rheme (Halliday 1985:278), in the progression of real-time reading, each rheme at various levels will join its paired theme to serve as the 'given' portion necessary for readers' meaningful processing of the subsequent part of the information structure. For instance, if the high-sounding sentential theme a truth universally acknowledged has created a suspense, in their search for its solution in the that-clause as the sentential rheme, readers are immediately given the clausal theme, a single man, which carries the information about gendre and marital 
status necessary for processing the following information in the clausal rheme. The segmentation has also enabled us to see that the right-branching presentation on the sentential level is compounded by the two right-branching post-modification structures on the phrasal level (that is, a truth universally acknowledged as against 'a universally acknowledged truth' and a single man in possession of a good fortune as against 'a wealthy single man'). This should not be considered as coincident, as in this way the information on three levels of the sentence, i.e. sentential, clausal and phrasal, is presented in a storytelling-like forward-pointing manner of theme-rheme formulation, which is reinforced by the syntactic, lexical and phonological cohesion already identified above. All this functions to constitute, as it were, a compelling doorway to the textual edifice of the novel as a whole.

\subsection{Chinese translations examined}

The discussion so far may be good for a linguistic criticism of the sentence per se; yet for a Chinese translator, what is crucial is whether the sequence, as well as other linguistic devices, of the sentence can be kept up in a Chinese target text, since the sequential features of the source text have been found to be effective more in a psychologically universal than culturally or linguistically specific sense. Apart from the stylistic tone-setting significance Leech and Short (above) have noted of this sentence in particular, Nord (1991:202) has highlighted the importance of the 'beginning of a long text, particularly in fiction' as 'the key' to the text's interpretation in translation in general, pointing out that:

Therefore, a thorough analysis of the beginning should be the first step in translating a novel. [...] If the translation skopos requires equivalence of effect - as appears to be the conventional skopos of literary translation in our culture today - these stilistic [sic.] devices should be reproduced in the translation.

Judging by the following two translations, however, Chinese syntax may appear to be in favour of a formation similar to OBSERVATION + CONCLUSION in [2. iii] above: ${ }^{3}$

[2. tr.i]

凡是有錢的單身漢, 總想娶位太太, 這已經成了一條舉世公認的真理。

[Back-translation] Every moneyed bachelor always wants to take a wife, this has already become a universally acknowledged truth.

(Wang Keyi tr.《傲慢與偏見》)

[2. tr.ii]

一個擁有豐厚資產的單身漢, 一定需要一位太太, 這是普天下公認的真理。

[Back-translation] A bachelor in possession of a good fortune is bound to need a wife, this is the universally acknowledged truth.

(Li Su tr.《驕傲與偏見》)

Both versions are perfect syntactic bearers and (propositional) information carriers in their own right. A closer examination of each of them as stylistic marker of the opening of the novel, however, reveals some mismatches between the translations and their source text in terms of information structuring that cannot be justified on the grounds of any supposed social functions of the target texts in the target culture. 
Firstly, both betray a downgrading in register (caused, e.g., by the colloquial word 單身漢 'bach'). And secondly, some inaccuracies have caused the translations to drift further afield. For instance, must be in want of a wife in the source text is quite different from always wants to take a wife in [2. tr.i], as the former indicates a (social) necessity while the latter pertains to (personal) intention or even desire; and while the source text is modalized by must (relating 'almost certainty' rather than 'duty, see above), [2. tr.i] is emphasized by 凡是 (virtually 'any and every') and 總 ('always'), and [2. tr.ii] by 一定 ('to be bound to'), both are determinate to the degree of 'certainty' that allows no exception. And [2. tr.i], probably due to a Chinese conception of what a 'truth' is, has carried a suggestion that the idea has been gaining currency - has already become - which sounds like a committed remark imposed on the target text.

The most gross disparity between the translations and the source text, however, is in the sequential structuring of information, as both translations adopt a marked left-displaced-subject ordering, which appears even more decisively close-ended than [2. iii]. Such a switch from right-branching to left-branching was defended strongwordedly by Sun (1997:11) on the grounds of safeguarding target text's idiomaticity (see Zhu forthcoming, for a critical discussion). It is interesting to note as well that at the phrasal level, the two right-branching head-modifier combinations have been similarly reversed to a static close-ended relation of pre-modification. The reason for such an alteration could be that, grammatically speaking, Chinese syntax does not normally accept an attributive phrase as post-modifier as much as English syntax does. As a result, what we have observed above as the psychological effects of the cohesive right-branching sequence of the source text has become unaccounted for; hence in a real-time process of reading, neither of the translations will function as efficiently as the source text does to open a compelling doorway to the textual edifice of the novel as a whole. ${ }^{4}$

With this awareness of the difference between an ASSERTION + ENUNCIATION and an OBSERVATION + CONCLUSION sequence, the whole challenge of translating the sentence, in this study, boils down to one key question: Does the Chinese language have any native or idiomatic pattern to begin a story in a right-branching, forwardpointing manner as English does, as in this case to effect an ASSERTION + ENUNCIATION speech-act sequence?

The awareness prompts us to look beyond those translations and explore further into the repertoire of Chinese syntactic resources, where a so-called jianyushi (兼語式) pattern presents itself. The right-branching formation it promises is congruent with the existence-related there-be construction in English, in that it allows new information to come at the end. As for the two post-modifier phrases in the source text, the textual perception of their functions has also prompted us to treat the modifiers, when the phrases are rank-shifted to the level of clause, as rhemes with new information to appear after the theme (i.e. the Head), instead of as grammatical attributives that have to be put before the noun-head. In this new, informationial light, the paratactic nature of Chinese morphology and syntax is found to allow ample room for such forward-pointing, right-branching theme-rheme combinations, to accommodate a translation as the following one, which enables an ASSERTION + ENUNCIATION sequence: 
[2. tr.iii]

有這麼一條真理舉世公認：單身男人擁有一大筆財產, 就必定需要一個太太。

[Back-translation] There is such a truth acknowledged by the whole world: a single man possessing a good fortune must need a wife.

The information structure can be segmented as follows:

FIGURE 2

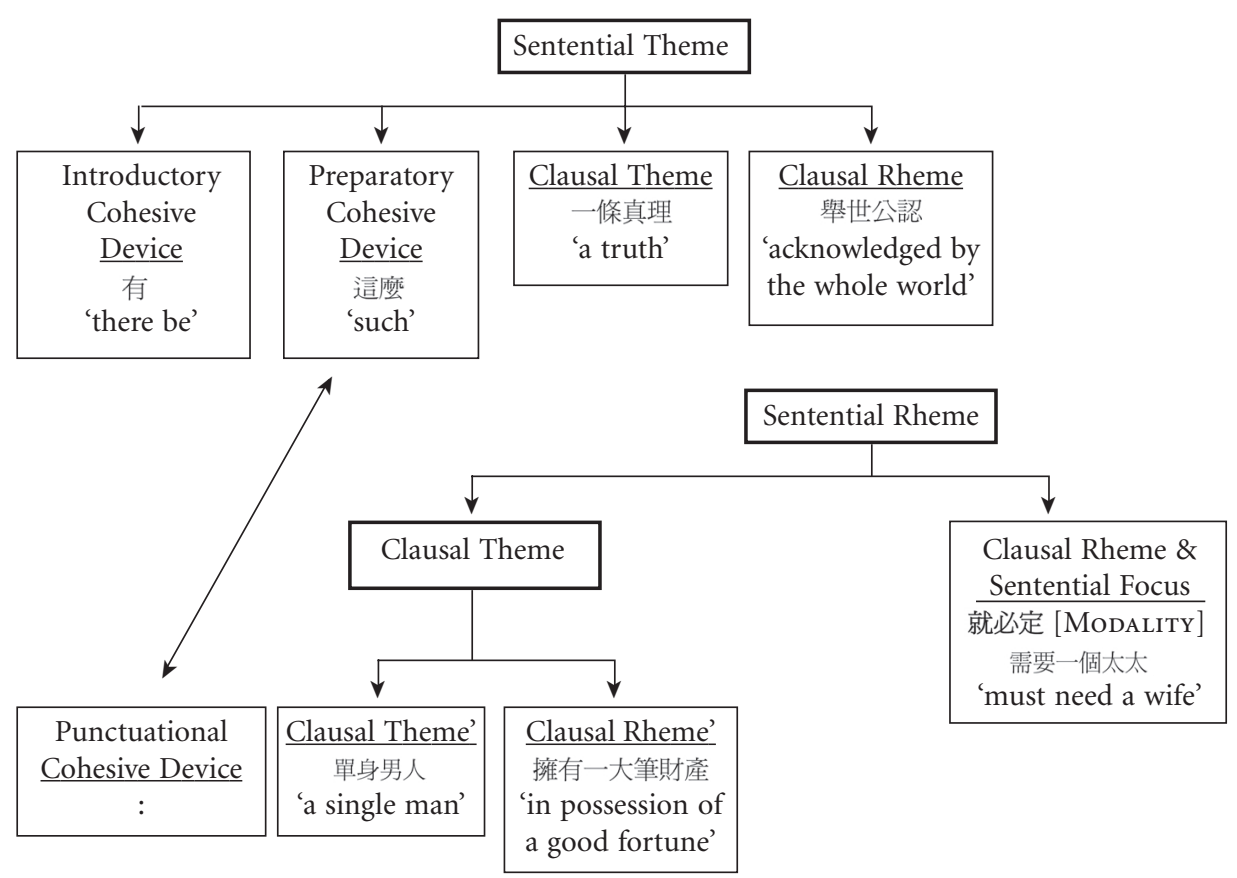

Or:

有 (Introductory Cohesive Device) 這麼 (Preparatory Cohesive Device) 一條真理 (Clausal Theme)/舉世公認 (Clausal Rheme) \{Sentential Theme\} ///: (Punctuational Cohesive Device responding to the initial cohesive devices) 單身男人 (Clausal Theme') / 擁有一大筆財產 (Clausal Rheme') [Clausal Theme] // 就必定 (MODALITY) 需要一個太太 [Clausal Rheme \& Sentential Focus] \{Setential Rheme\}.

The treatment of the two phrasal modifiers not as grammatical attributives but as informational rhemes, if it reveals a plausible way to optimize accountability for the source text's effective formulation, is a result of the textual awareness of speech-act sequencing on various syntactic levels. It embodies a shift of focus in the decisionmaking process of translation, that is, from grammar to information structuring.

Between languages, to be sure, it is meaningless, if at all technically possible, to try to seek sequential identity between a source-text and a desirable target-text sentence without an awareness of their (potential) textual integrity. That is to say, plausible and justifiable management of information structuring in translation has to take into consideration the function of the textual formulation within the formal confines of the target language. (Just consider the different positioning of attributive 
adjectives between English and French, given the possible semantic difference between phrases such as brave homme - 'worthy man' and homme brave - 'courageous man.') It is such an awareness of the needs, the constraints and the possibilities that will prompt a translator to work towards a stylistically more effective rendering. Thus to cultivate such an awareness should be viewed as one of the major tasks in translator training or translation teaching. ${ }^{5}$

With this understood, the present case study has sought to demonstrate that the concern with the sequentiality of sentential information structure can be taken as a basic reference for decision-making in cross-language information management - in source-text interpretation, target-text construction, and translation quality control alike. Against textual/functional implications of sequentiality, reasons for any alteration of the sequence can be more specifically observable or explainable - for instance as an obligation to the target-language linguistic norms, a sign of the target-text's stylistic inclination, a case of reshaping the sequence for a matching or desirable effect in a new intertextual culture of the target text, or a failure to identify a more effective target sentence pattern for the target text. As Halliday (1985:290) points up:

The organization of text is semantic rather than formal, and (at least as far as cohesion is concerned; $[\ldots])$ much looser than that of grammatical units. [...] it is important to be able to think of text dynamically, as an ongoing process of meaning; and of textual cohesion as an aspect of this process, whereby the flow of meaning is channelled along the speaker's purposive courses instead of spilling out aimlessly in every possible direction.

As such, the sequence of information presentation, by being semantic, is more pliable and amenable than the syntactic formation and can thus be linguistically formulated more positively to create an effect. It follows that in translating it is the semantic configuration, cemented by cohesion and coherence, rather than grammatical formation bound by rules, in a source language sentence, that is to be relayed in the formulation of its target-language counterpart. In consequence, creative and textually-conscious use of the syntactic resources of the target language, to a great extent, means engineering a target-language mode of information presentation that matches the source-language one in function and effect, even though the syntactic pattern has to be altered in the sense of grammatical categorization.

\section{Case Three: From sentences to the text}

In this case study, we will observe how cohesive factors can be more definitely accounted for in the construction of thematic structures in the target text 'as an ongoing process of meaning' (Halliday above).

\subsection{A thematic analysis of the source text}

The English source text to be examined in this section is a concocted postcard text borrowed from McCarthy's Discourse Analysis for Language Teachers (1991):

(1) I'm sitting here at my desk writing to you.

(2-1) Outside my window is a big lawn surrounded by trees,

(2-2) and in the middle of the lawn is a flower bed.

(3) It was full of daffodils and tulips in the spring. 
(4) You'd love it here.

(5-1) You must come and stay sometime;

(5-2) we've got plenty of room.

The reason for selecting this text for an intensive study in relation to translation is similar to the previous two cases: the text has been submitted to discourse analysis in the environment of the source language. But in particular this text has been intertexually compared in the source with two alternative, less effectively organized versions (McCarthy 1991:53-55). In other words, the effect a source text might have on the native reader, which translators have tried so hard to perceive or conceive but without much success, has in this case as well as in the previous two been analytically documented by intellectual readers for a translator's reference. The text proper used here has been re-arranged sentence by sentence in list form for the convenience of discussion. Although there is little clear-cut distinction between the sentence and the co-ordinate clause in terms of textual status (Zhu 1999:440), in [3] above we have indicated the hierarchical difference of their syntactic status by way of numerical sequence. As mentioned above, in its original source, the text is set against a couple of thematically flawed variations, which we will refer to later in our discussion as further support for our argument that textuality is sentence-based.

As a postcard message, the textual theme is an 'interactional' one (see Berry 1989 for interactional themes), i.e., You the addressee, about 'you' to visit 'I.' But the intention of the interaction is not made known until a series of sentential speech acts have led to it in the second half of the text, where it occupies the focal position, i.e., sentence (5-1). The discoursal speech act is one of greeting (as a postcard usually does) with mild persuasion (as the text suggests), which entails equality of the role relationship in the interaction. This determines the mode of presentation and distribution of information throughout the text, that is, the ordering of sentential speech acts. The text works itself out in the following sequence when the series of speech acts are judged by their illocutionary force in the composition:

SETTING-UP OF RELATION (1) + INVOLVEMENT THROUGH DETAIL DESCRIPTION (2-1)-(3) + TRANSITION THROUGH EVALUATION FROM A PRESUMED ADDRESSEE'S POINT OF VIEW (4) + Persuasion (5-1) + ASSURANCE (5-2).

The sequence as it stands serves the illocutionary purpose of the text adequately: for instance, sentences (1)-(4) might not be as necessary as, say, information concerning TIME had it been a case of invitation; and only sentence (5-1) would be needed had it been an order or command.

Tracing the organization of the text sentence by sentence, we can see that sentence (1) as information carrier is apparently redundant in terms of ideational meaning, as what it does seems no more than stating a self-evident fact (for which the existence of the postcard will speak eloquently), nothing contradictory to the norms of letterwriting. Although it is common sense that 'language-in-use is not free of redundancy' (see Gutknecht and Rölle 1996:235-237 also for a critical discussion of Kussmaul's 'minimalist approach' to translation), what has to be pointed out here is that redundancy can serve as a stylistic marker to secure more effective acceptance. As in this case, the ideationally redundant beginning of the text marks an interpersonally significant style. It serves to establish or confirm the desired communicative relation. The implicature in such flouting of the Gricean Maxim of Quantity (i.e., 
'Make your contribution to the conversation just as informative as is required.') is probably 'I am thinking of you.' Also it sets a leisurely conversational tone for the text by virtue of low density of transactional information, i.e., information that is intended to change the addressee's schema of world knowledge. (Compare a business letter beginning with 'I am writing to inform you ....')

The tone once set prevails, though the semantic density picks up as the text develops. The tone as such prevents sentence (5-1) from being interpreted as an order or command, although, in isolation, it sounds like one. Last but not least, the opening sentence is thematically significant for the unfolding of the textual information presentation, as from the detail 'at my desk' one is likely, subconsciously though, to develop a 'room image' (from one's own schema of letter writing in a study, bedroom, or office, etc.) which normally contains a window-element. So the theme of (2-1), outside my window, is experientially, though implicitly, connected with the rheme of (1). This is one of the reasons why [3. i] and [3. ii] below, two variations provided by McCarthy for comparison, are thematically unsatisfactory.

Sentences (2-1), (2-2) and (3) are devoted to details. As for the relation between details and propositional information in narrative texts, Tannen makes a useful observation:

If communication were only a matter of conveying information, then the [details] would not add materially to the story. [...] And yet [the details] do contribute to the story; they make the story.

(Tannen 1989:139, original italics)

This holds in our current discussion as well. One of the reasons for the presence of these detail-information carriers in the text, besides the function of spatial orientation mentioned by McCarthy himself, is that as stylistic markers they provide not only factual details to convince, but immediate details to involve. The immediacy implies the writer's personal involvement with the visual perception and mental recollection accompanying the act of writing, which, in turn, works towards an interpersonal involvement on the reader's part. This is achieved by putting the reader 'in the picture' through the visual details depicted in (2-1) and (2-2) and 'in the time' through the temporal depth provided by the past tense in (3). So, by approaching the text as a dynamic congregation of sentences, we can see more clearly that what might have seemed no more than a trivial detail on the text level could be the main textual thrust of the sentence in which it appears.

If sentence (1) is about 'I' (the theme/topic) and sentence (2-1) starts a sentence group about 'outside my window' (the theme/topic of (2-1)), then the cohesive hinge on which the two parts hang together is the word my which contains an element of the theme of sentence (1). Now, after the presentation of details, there is a strategic need for a switch of focus to 'you,' whom the whole text is about. The transition takes place in sentence (4) where 'you' is given the thematic prominence. Meanwhile, in the rheme the new information contains a mental process of reaction, i.e., 'love', (for different kinds of mental processes of transitivity, see Berry 1975:152), which forms an emotional connection between the new theme 'you' and what the preceding part of the text is about: 'it.'

Sentence (5-1) can be regarded as the illocutionary focus of the text, the climax in the discoursal development. This textual focus of persuasion is supported imme- 
diately (i.e., with the sentential boundary marked by a semicolon instead of full stop to indicate textual closeness) with an assurance in (5-2). It is notable that the theme of (5-2) has switched back to the first person but extended to plural 'we,' in this way it finishes off the text with an implication of a promise (of a pleasant stay, as it were) and an (unanimous but tentative) invitation or suggestion.

Thematic structuring offers another perspective for us to see how information distribution in the text has helped the execution of its constituent illocutionary acts, 'as a means of creating topic frameworks and as an example of audience orientation' (McCarthy 1991:56). The two patterns of inter-sentential thematization that stand out in [3] are: (a) the serial or linear pattern, where the rheme of the previous sentence contains an element that becomes (part of) the theme of the following sentence, which is seen from (2-1) to (3), where detail descriptions occur; (b) the repetitive or reiterative pattern, where the theme of a sentence is repeated as the theme of the following sentence(s), which is seen between (4) and (5-1), when the text develops into direct persuasion.

Text [3] above has been set in the original source against a 'highly unlikely' version, [3. i], and a 'jejune' one, [3. ii], below:

\section{[3. i]}

Me, I'm sitting here at my desk writing to you. What's outside my window is a big lawn surrounded by trees and it's a flower bed that's in the middle of the lawn. When it was full of daffodils and tulips was in the spring. Here you'd love it. It's you who must come and stay sometime; what we've got is plenty of room.

[3. ii]

I'm sitting here at my desk writing to you. A big lawn surrounded by trees is outside my window and a flower bed is in the middle of the lawn. It was full of daffodils and tulips in the spring. You'd love it here. You must come and stay sometime; we've got plenty of room.

In both [3. i] and [3. ii], unmotivated use of fronting devices and impoverished management of information presentation have caused a want of cohesive description of the imaginary writer's visual and mental experience in a linear progression of orientation, which in [3] is effected by the serial pattern of thematization from (2-1) to (3) (see Linde and Labov 1975 for comments on typical realizations of such listener-orientation in spatial descriptions). There is also a lack of involving rhythm as well as appropriate thematic prominence as secured by the repetitive pattern of thematization found from (4) to (5-2) in [3], although effects of repetition may not be evident in a short text like this. (For more extensive accounts of the effects of repetitive patterns in terms of communicative involvement strategy, rhythm, and attitudinal evaluation, see e.g., Tannen 1989:2, 3, 29, 37, and 50-51; Ishikawa 1991. For a discussion of the patterns in the context of translation, see Nord 1991:205ff, where the author observes that the serial pattern 'keeps the narration flowing to some degree,' while the repetitive pattern 'conveys a high degree of density and a minimum of "communicative dynamics"' (p.208).)

Such a comparative observation of the three texts enables us to see more clearly the significance of inter-sentential coherence in text formulation. In isolation, all those sentences in [3. i] and [3. ii], as syntactic bearers and information carriers, are grammatically as sound and ideationally as informative as their counterparts in [3]. Judged 
from the textual point of view, however, they fail to attain their textual integrity, because as stylistic markers they are unable to hang together to mark a textually and intertextually acceptable text, in a socio-cultural context where text [3] is considered fit.

\subsection{A thematic comparison of the source text and its translation}

In the previous section we have described the correlation between intra-sentential thematic arrangement and inter-sentential coherence in textual organization and how the former could facilitate or hamper the realization of the macro speech act of the text. Once more it has been demonstrated that the textual completion and communicative competence of a text as a cohesive and coherent entity relies heavily on the textual integrity of its constituent sentences. In this light, textual distortions at the sentence level such as unaccountable expanding, pruning, altering or reshuffling can lead to textual disorganization as found in [3. i] and [3. ii] above, and the resultant target version should not be deemed a translation in the true sense of the word.

In our view, therefore, what text linguistics alerts a translator to should be the necessity and possibility of more purposive and rigorous thematic management in a sentence as textual unit, and not the opposite. This can be further illustrated by our analysis of a proposed Chinese translation of [3] as follows:

[3] and [3.tr]

(1) I'm sitting here at my desk writing to you.

(1. tr) 我這會兒正坐在桌邊給你寫明信片呢。

('I this moment just sit at desk side to you write postcard ne TONE-PARTICLE')

(2-1) Outside my window is a big lawn surrounded by trees,

(2-1. tr) 窗子外邊是一大片樹木環繞的草坪，

('window outside is one big pian CLASSIFIER tree:wood surround-de Associative lawn')

(2-2) and in the middle of the lawn is a flower bed.

(2-2. tr) 草坼當中是個花壇,

('lawn in:the:middle is ge CLAssifier flower:bed')

(3) It was full of daffodils and tulips in the spring.

(3. $\operatorname{tr})$ 春天時開滿了黃水仙和棱金香。

('spring-time opened-full-le PERfective daffodils and tulips')

(4) You'd love it here.

(4.tr) 你會喜歡這兒的。

('you would like here de PARTICLE ASSERTION')

(5-1) You must come and stay sometime;

(5-1. tr) 甚麼時候你應該來住上一陣,

('you some time must come here live-up a:while')

(5-2) we've got plenty of room.

(5-2.tr) 我們房子很寬敞。

('we house quite spacious')

Since [3] and its Chinese version are culturally and discoursally compatible in information structuring, that is, they observe a similar process of perception (i.e., orientation) and communication (i.e., greeting with persuasion), we can concentrate 
on how a natural and effective rendition is achieved by upholding the textual integrity of the sentences as independent but not autonomous functional UTs.

In constructing the informational pattern of sentence (1. tr), we have to bear in mind its source-language counterpart's interpersonal significance and how it sets the discoursal tone by low density of transactional information, as we have related above. Although in (1.tr) redundancy is as abundant as it is in (1), for the sake of the target text's naturalness, (1. tr) is allowed to contain elements of a different or adjusted ideational meaning, i.e., to carry different redundant information in order to perform a similar stylistic marking function. The spatial here being replaced by the temporal 這會兒 ('at this moment') is a case in point. By the same token, the reflexive possessive my goes implicit in both (1. tr) and (2-1. tr), as Chinese syntax tends to suppress an unmarked possessive; while the postcard-element has been brought to the surface because an object is grammatically required in the Chinese text. The phrase to you has also been re-located to increase naturalness.

In sentence (2-1) the most cohesive theme for both Chinese and English versions is 'outside (my) window'; the translation would sound as odd as [3. ii] had 'the lawn' been fronted to the thematic position, (A room-image normally entails a window; but a window does not necessarily open to a lawn, so to speak.) as in the following variation where the end-focus in the rheme is given to 'trees':

\section{(2-1. tr. i) 窗外的草坪很大, 四周環繞著綠樹。}

[Back-translation] Outside the window the lawn is big, surrounded by trees.

So long as we keep 'the lawn' in the rheme as an item of new information, when it becomes part of the theme of (2-2. tr), serial thematization will support the cohesion between (2-1. tr) and (2-2. tr) as it does in the source text.

The omission of the co-ordinator and in (2-2. tr) is worth noting. Conjunctions such as co-ordinators and subordinators, according to Halliday (1985:51), are inherently thematic' (i.e., with what follows still having thematic force), but it is the logical meanings of these particles that is chosen by the speaker/writer each time to link relevant sentences or clauses. This is of particular importance in translating, as the words expressing those meanings can be assigned thematic status in one language, e.g., English, but left implicit in another, e.g., Chinese. ${ }^{6}$ In Chinese, the most neutral meaning of and in connecting parallel structures is usually 'iconicized' by the juxtaposition of the structures concerned. Therefore the meaning of connection tends to appear more marked (e.g., in terms of adversativeness or emphasis) in translation if and is translated explicitly into Chinese as, say, 而且 ('moreover'). (The translating of and into Chinese is extensively illustrated in Chen 1985:70-73).

The translating of sentence (3) offers a few insights into the differences between Chinese and English in reference-coherence mechanism and how they can be tackled through intra-sentential management of information presentation.

First, one may have noticed that it in (3) does not surface in (3. tr). The 'neutral' nominal demonstrative (Halliday and Hassan 1976:58) of $i$, according to McCarthy's observation, 'is used for unmarked reference within a current entity or focus of attention' (McCarthy 1994). As in (3), it helps to retain the referent 'flower bed' in focus without marking it. In Chinese such a textual function is usually performed by the zero-demonstrative (Xu 1987), and this is the case in the translation of (3). What is of interest though is that (3. tr) thus produced is more closely hooked anaphorically 
to (2-2. tr), as with the zero-demonstrative the theme of (3. tr) overlaps the rheme of (2-2. tr) on the entity 'flower bed,' as a means of cohesion. As a result, no full stop is desirable to separate the two, and this portion of the text in [3. tr] has merged, so to speak, into a 'run-on' sentence covering the whole series of detail descriptions from $(2-1)$ to (3) in [3]. Rank-shifts as such are far from uncommon in translating and can take place on different levels, but still their textual implications can be better observed and assessed in the thematic perspective of the sentence concerned.

Secondly, in (3) the phrase in the spring has been assigned an unmarked position at the end of the sentence as part of the rheme, in (3. tr) this circumstantial component, as required by Chinese syntax, is raised to the thematic position, with the formally implicit but conceptually inferable 'flower bed' as the other part of the (complex) theme. This is actually a case of zero-subject in Chinese syntax, which postpones the actor ('daffodils and tulips') to the end as part of the rheme, and thus arranges the presentation to have 'in the spring' and 'over the flower bed' together as given information, fulfilling the thematic cohesion of the text.

Translating with less textual awareness, that is, regarding sentences more as formal than functional units, might have turned out versions that are grammatically correct but textually less effective. For instance:

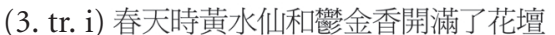

[Back-translation] In the spring daffodils and tulips bloom over the flower bed.

(3. tr. ii) 黃水仙和鬱金香春天時開滿了花壇

[Back-translation] Daffodils and tulips in the spring bloom over the flower bed.

Both have fronted 'in the spring' and 'daffodils and tulips' and therefore much weakened the cohesive/coherent link existent between (3. tr) and (2-2.tr). As a result the information presented is switched abruptly to being about 'in the spring' (3. tr. i) or 'daffodils and tulips' (3. tr. ii) as the given information, yet neither of them has been 'given' to the reader, textually or contextually. So, for a moment the reader may feel jostled out of the stream of the textual flow on to some discursive details, and the textual effect of the target version is disturbed.

In translating (5-1), since grammatically we have to front 甚麼時候 ('some time') in Chinese, the question is where to relocate it, owing to the syntactic flexibility in positioning adverbials in Chinese as well as in English. In this connection, an alternative, namely (5-1. tr. i) below, is worth noting:

\section{(5-1. tr. i) 你甚麼時候應該來住上一陣}

[Back-translation] Sometime you should come and stay for a while.

As in the above Chinese texts, the combinations of 'sometime' and 'you' can be regarded as a complex theme, the choice of which of the two to come first will not affect the sentence's information structuring as such. What makes a difference, though, is that to have 'sometime' at the beginning would give the text some variety (in terms of 'texture,' to be sure, a quality complementary to syntax and textuality as 'the colouring and fleshing of the text' by Nash's 1980:46 metaphorical description) while maintaining the effect conveyed by thematic repetition, as seen in (5-1.tr); yet in Chinese discourse at large, a series of two (or more) consecutive sentences led by the same pronoun is generally saved for more charged expression of emotion, especially when the sentences are short. 
On the other hand, one could anaphorically delete the pronoun 'you' and come up with the following version:

\section{(5-1. tr. ii) 甚麼時候應該來住上一陣}

[Back-translation] Sometime [you] should come and stay for a while.

A point to note is that the deletion will attach the sentence closer to the previous one at the cost of the effect induced by the thematic repetition, and may convey a tone more of friendly casualness than persuasiveness.

In translation, the grammatical pattern of (5-2) has been radically altered in order to make (5-2.tr) a natural syntactic bearer while carrying a similar amount of ideational information. However, the function of stylistic marker still insists on the choice of 'we' as the theme of (5-2.tr) so as to attach the sentence as a more competent textual unit to the text at large. This consideration has ruled out some other options that express the same ideational meaning but have other element(s) as the theme, for example:

\section{(5-2.tr. i) 房子我們這兒很寬做}

[Word-for-word translation] 'house we here very spacious,'

which, being about 'house,' may imply a presupposed worry about the availability or condition of accommodation. In (5-2. tr), however, with 'we' as the topic, 'house is spacious' consists grammatically of a 'subject + predicative adjective' construction to form the comment confirming something about 'we,' who send the invitation. (The sentence pattern is referred to by some authors as a 'double-subject' construction, see Li and Thompson 1981: sec.4.1.4; but this position does not seem as congruent with theme-rheme or topic-focus approaches.)

The effectiveness of the thematic structure of a sentence as a textual unit can be examined and assessed more precisely only in the light of textuality. This is why a translation should be finalized on the text/discourse level where the judicial unit for judgement (Zhu 1999) is based. The textual experiment designed for this case study demonstrates how a rigorous observation of a sentence's textual integrity as realized in textualization has enabled [3. tr] to develop in a pattern of coherence strikingly similar to that of [3] in communicative function, despite various local adjustments owing to different linguistic preferences. From the discourse point of view, the serial thematization from (2-1. tr) to (3. tr) and the parallel from (4.tr) and (5-1. tr) can be expected to contribute as effectively as their counterparts in [3] to the completion of the predominant speech act of the text as a whole. As such, in this case study as well as in the previous ones, the final justification left for our concern with the sequentiality of information structuring seems to be: whether one, as a target reader, will be intellectually and emotionally 'persuaded' by a presentation of information in such a sequential mode? Answers to which may not be easy and ready, and are beyond the scope of this paper; but the raising of this question itself will help to put issues such as reader response in a more specific perspective, and can expose translation studies to insights furnished by relevant disciplines, such as sociolinguistics and cultural studies (e.g., for the study of power/role relations and ideological manipulation reflected through translation), cognitive linguistics and psycholinguistics (e.g., for the study of mental representation, 'virtual translation' and translation process), and narratology and creative writing (e.g., for the study of adaptation and re-writing as translation). 


\section{Discussion}

What makes text translation different from sentence translation, in essence, is not the size of the text or UT involved but the emphasis on a textual perspective in which a (part of a) text, in this case a sentence, can be assessed, managed and manipulated as a functional unit to serve a certain translational purpose.

This perspective underlies a variety of text-based approaches to translation studies. For instance, when we perceive a text in the light of 'text act,' we are looking at it in terms of 'the predominant illocutionary force of a series of speech act' at the level of sentence (Hatim and Mason 1990:78, italics added), or rather 'text sentence' in the text-linguistic model of translation described in Neubert and Shreve (1992:23). When Nord (1997), in opposition to the traditional "'horizontal" segmentation in the chronological sequence of linguistic elements ${ }^{7}$, puts forth the top-down notion of 'vertical translation units,' 'bringing together all these elements [i.e., 'various linguistic or non-linguistic elements that can occur at any level anywhere in the text,' for example, the variety of 'irony markers' discussed in Nord 1991:218], the text is presented 'as a hyper-unit comprising functional units that are not [horizontal]rank-bound (Nord 1997:69). If the text is perceived as such a functional [hyperJunit, then it is worth noting that in Nord's (1991) framework, 'the notion of text function means the communicative function, or the combination of communicative functions' (p.70), in which the communicative function could subsume, following Jakobson, the 'four basic functions of communication,' i.e., the referential, the expressive or emotive, the operative, and the phatic (p. 42), while communicative functions could mean the 'communicative functions of sentences' (p. 70) and thus individual (illocutionary) speech acts. In this way, Nord, similar to the approach of text act, presents speech acts, which are largely formulated at the level of sentence (cf. Zhu 1996c:344), in the perspective of the text (cf. Nord 1991:70, where she criticizes Thiel for failing to do so). She has also rightly pointed out that ' $[\mathrm{A}]$ mong the extratextual factors it is primarily the aspects of intention, medium and text function that are characterized by particular sentence structures' (Nord 1991:118); and intention, or intentionality, according to Hatim (1999:205) subsumes 'the whole notion of "speech acting"'

Thus, through speech act in the guise of intentionality, sentence structures are made accountable for the function or 'act' of text in the process of textualization. And the textual in the Hallidayan system of functional linguistics is the function that enables, through the thematic structuring of information, the other two functions, i.e., the ideational (relating to transitivity) and the interpersonal (relating to mood) (see Bell 1991:121 and 159n.6). Indeed, the theme-rheme structure (TRS) has featured prominently in Nord's system, too, albeit the 'purely semantic' TRS is perhaps more in the tradition of functional sentence perspective than in that of the Hallidayan systemic-functional linguistics which postulates a position-related parsing of theme and rheme (see e.g., the Checklist for Sentence Structure, Nord 1991:120, but also 118, 205, and 243; and see Baker 1992:ch.5 for a comparative discussion of the two traditions).

Perhaps it is in the sense of how to make semantic and structural details at the sentential level (e.g., cohesion through lexical repetition) more functionally accountable for the extratextual or social functions of the text that Nord's approach can join 
forces with Hatim's (1999) model of Critical Translation Studies. The Hatim's, which 'ultimately seeks to combine the three perspectives of linguistics, intercultural communication and translation theory', is informed by systemic-functional linguistics and critical linguistics (Hatim 1999:205; the latter as an extension or development from the former, concerns itself with the power or social-role relationship that is realized through textualization, cf. Fowler 1996).

In their application of the theory of speech act to linguistic descriptions, these text-based approaches, to be sure, have focused on the illocutionary rather than seeking a more comprehensive or balanced exercise that incorporates locution, illocution, and perlocution as they should. The situation may be understandable, as the perlocutionary act has been regarded as falling 'largely outside linguistics' (Fawcett 1997:127, see also Thomas 1995:51; but cf. Zhu 1996c:345-346).

Gutknecht and Rölle (1996), on the other hand, have included in their bottomup approach the perlocutionary as one of the pragmatic factors that bridges the gap between linguistic factors relating to illocutionary and nonlinguistic factors relating to situation and culture (p. 127). Their application of perlocutionary act has led to a rather simplistic understanding of effect, i.e., a principle of 'identity of effect correlated with identity of linguistic means employed':

Translation equivalence on the level of perlocutionary would mean that the TL rendition produces the same effect in the hearer as does the SL original. This identical effect could be expected if identical means are employed, that is, if the same acts of reference, predication, and illocution are performed; [...]. (p. 137)

Since some factors or features of textuality such as relevance, intentionality, intertextuality, and acceptability are rarely, if at all, identical between the source and a target text, the notion of equivalence has been relativized (sec.8.5) in their argument for translating by factors, which in turn means translating under a relevant set of speech-act felicity conditions (pp. 303-305).

Gutknecht and Rölle's approach is similar to the one adopted in this study in that it bases its observation on the sentence as the key level, accountable in terms of speech act to the text through an 'intersentential dynamism' in the use of e.g., articles, adverbs, pronouns, tense, and conjunctions (p. 233, see also Bell 1991:111 for such deictic mechanisms that knit sentences together in formulating a text). To facilitate a more comprehensive and balanced engagement between speech act theory in its three aspects and textualization in terms of theme-rheme and topic-focus structuring to account for the realization of a sentence's functional potential in a text, however, it is worth noting that what the illocution-perlocution relationship alerts a translator as a language user to is 'the distinction between attempt and achievement' (Austin 1975:106) of the effect of a speech act. And, unlike convention-governed illocutionary intention, perlocutionary effects are realized more on an individual than a collective or cultural level, in either the source- or the target-text environment, or a conflation of the two where translation takes place, because such effects are on individual information receiver's feelings, thoughts and/or behaviour. This can further be seen in the development of speech act theory as observed by Coulthard (1985:20): for Austin, the illocutionary force is more speaker-centred as the successful realization of the speaker's intention, while for Searle it is more listener-oriented as a product of the listener's interpretation. 
To ensure the viability of a textual perspective on the part-whole accountability in textualization, we illustrate in this study the feasibility of the sentence as the key functional unit. Such a unit provides a standpoint from where speech acts in a text as a meaningful sequence can be observed along the sequence of theme-rheme/topicfocus at levels below the sentence, as in Case Two, as well as on and above the sentence, as in Case Three. This is because in its textual integrity a sentence as a syntactic bearer houses a hierarchical and sequential structure for speech acts, which can be submitted, when the sentence is viewed as an information carrier, to theme-rheme and topic-focus analysis for its potential effects, so as to make the structuring of speech acts textually meaningful for the social function the source/target text is intended to perform. The effectiveness of the performance, then, renders the formation of the sentence relevant as stylistic marker.

It is in this light that we have illustrated the significance of the argument that in translating 'decisions made at any other language levels will be duly reflected within the contour of the sentence, the primary building block for TL text construction,' and that ' $[\mathrm{H}]$ owever the translator decides, the fact remains that paragraphic [and textual] patterns draw heavily on sequential arrangements of sentences for their development' (Zhu 1999:440 and 441, original italics).

\section{Conclusion}

Insights provided by the study of language function and information structuring in the form of discourse analysis and text linguistics have enabled us to apply the theoretical concept of UT more effectively and profitably in the teaching and practice of translation. A textual perception of the UT as functional unit, as substantiated in this article, will help clear up some deep-rooted confusion or worry over its application or applicability, which has been rightly aired by Newmark, that is, 'Clearly the text cannot be the Unit in the "narrow" sense defined by Vinay and Darbelnet. That would be chaos.' (Newmark 1988:55). Our argument in this article is that taking the sentence as the key functional UT with its textual integrity will highlight the importance of sentential analysis for textual formulation as a whole, so as to make the units along the rank-hierarchy of both the source and the target language functionally accountable for the interpretation of the source text, for the decisions taken in formulating an emerging target text, and for the explanations offered in analyzing a translational act. In other words, the discourse-sensitive rationale of translational behaviour, with its analytical methodology and explanation power informed by systemic-functional linguistics and speech act theory, will help, on the one hand, create an awareness of the accountability in translating between the semantic-syntactic formulation of information structure and the performance of intended illocutionary functions on both intratextual and textual levels; and on the other hand, encourage an openness to the achievement of the target text's perlocutionary (social) effect on its individual receivers in the new intertextual environment, which cannot necessarily be equivalent to that of the source text in its native environment, especially in the case of literary translation. 


\section{NOTES}

1. For a description of sentences of different patterns of 'branching', see Nash (1980:111ff). While the author's perception of branching is mainly in line with syntactic formation of English sentences such as the placing of adverbials or subordinate clauses, the characterization is in principle applicable to Chinese sentences, especially if we view the branching from a textual (in terms of thematic structuring) and interpersonal (in terms of illocutionary acts) perspective to explain a particular sentence's textual integrity. This is the position adopted in this research, which is hoped to make the syntactic flexibility offered by the so-called 'run-on' type of sentences in Chinese less rambling but more accountable for information management in translation.

2. Hatim and Mason (1990:60-61) have referred to Traugott and Pratt's classification of speech act as follows:

1. Representatives which seek to represent a state of affairs;

2. Expressives which express the speaker's emotions and attitudes;

3. Verdictives which evaluate and relay judgement;

4. Directives which seek to influence the receiver's behaviour;

5. Commissives which commit the speaker to an action;

6. Declarations which perform a particular action.

In this light, ASSERTION and CONCLUSION belong to the Verdictive because of the judgement they imply, hence pointing towards the 'managing' end; while ENUNCIATION and OBSERVATION belong to the Representative (perhaps in this case with an element of the Expressive), hence pointing towards the 'monitoring' end. (For a discussion of unevaluative monitoring and evaluative managing 'as two basic cognitive processing strategies' in translation, see Hatim 1999.)

3. Chang 1996 provides one more published version of a similar pattern, with a suggested revision which follows the source-text pattern on the sentential but not the phrasal level. Among the 11 Chinese versions published in the 1990s, as collected by Xiaoyuan Wang (private email, 5 May 2001), while one adopts a partially reversed pattern to the effect that 'It is universally acknowledged, that $[\ldots]$. This has become a truth,' there is only one, and the most colloquially rendered one, which follows the source text's pattern:

誰都知道, 單身漢有了錢, 第一件事就是要娶上個媳婦。

[Back-translation] Everyone knows, [when] a bachelor becomes rich, the first thing is to get a wife. The phrase-clause shift in this version, namely, from 'a single man in possession of a good fortune' to 'a bachelor becomes rich,' is found in one of the two additional published versions recorded in Chen (2001:9), that is, shifting to 單身男人一旦有了錢 ('once a single man has got money').

4. In his comments on the beginning passages of Pride and Prejudice, an English-language columnist, Puguang Yao, while providing his Chinese translation which follows the OBSERVATION + CONCLUsIon sequence 'to be in keeping with the idiomatic Chinese usage', notes that such a sequence has failed to create a similar effect of 'bathos' found in the source text (Mingpao, 5 December 2000, p. E5, my English translation).

5. Elsewhere (Zhu forthcoming), I have given a simplified account of this case study, with reference to the support from authentic language data for the idiomaticity of the proposed [2.tr.iii], and to its implications for theoretical understanding and teaching of translation. Here, it seems necessary to further point out that the almost stereotyped close-ended left-branching Chinese pattern that has enabled the obSERVATION + CONCLUSION speech-act sequence has an extensive influence on students' performance in translation, which in some cases has prevented them from producing a more coherent rendering. For instance, the following is back-translated from a passage in a recent MA student's translation project of Harry Potter and the Goblet of Fire by J.K. Rowling (London: Bloomsbury, 2000): (All italics are added.)

When Voldemort - the most powerful Dark wizard for a century, a wizard who had been gaining power steadily for eleven years - arrived at his house and killed his father and mother, Harry was a year old baby. At the moment Voldemort was lifting his wand at Harry; [...].

Compare: (1) the source text:

Harry had been a year old the night that Voldemort - the most powerful Dark wizard for a century, a wizard who had been gaining power steadily for eleven years - arrived at his house and killed his father and mother. Voldemort had then turned his wand on Harry; [...]. (p. 23)

And (2), a proposed version which presents a right-branching rendition: 
[Back-translation] The year when Harry was one year old, one night Voldemort arrived at his house. For a century this Dark wizard had been the most powerful wizard, and had been gaining power steadily for eleven years, he killed his father and mother, and then, turned his wand on Harry; [...]. The proposed translation, which is in natural and idiomatic Chinese too, has put the original rheme back in focus, which will advance the discourse of the story along a more coherent line: ...; and then, ....

6. Note in Li and Thompson 1981, conjunctions are not taken as part of the topic, given the difference between 'theme' and 'topic' as grammatical notions. See Baker (1992: Ch.5, esp. Sec.5.1.1.4) for a brief discussion of theme and topic. Different conceptions have led to different perceptions of the relationship between 'theme' and 'topic' though. For instance, Halliday, while identifying an ideational element termed 'topical theme' within the Theme (1985:54), has maintained (2001:4) that Topic + Comment in less specific use is the 'renaming' of Theme + Rheme (see also Fawcett 1997:87). In Lambrecht (1994), however, 'theme' plays 'a semantic role' while 'topic' represents 'a pragmatic relation' (p.342 n.11, see also p. 15) in which it is related to 'focus' instead of the traditional 'comment', a perception followed in the current study. The relationship between theme and topic has continued to arouse attention in the field; and there is a very recent publication by John Benjamins, i.e. The Theme-Topic Interface by María Ángeles Gómez-González, 2001, as announced in the publisher's Book Gazette Spring 2001.

7. One may wish to note that 'linguistic elements' referred to here should be viewed within the Linguistic instead of Text-linguistic Model described in Neubert and Shreve (1992:19ff; see also p. $26 \mathrm{ff}$ for the Computational Model).

\section{REFERENCES}

Alexander, L.G. (1988): Longman English Grammar, London and New York, Longman.

Austin, J.L. (1975): How to Do Things with Words (The William James Lectures in 1955), Oxford, Clarendon.

BAKer, M. (1992): In Other Words: A Coursebook on Translation, London and New York, Routledge. Bell, R. T. (1991): Translation and Translating: Theory and Practice, London and New York, Longman.

Berry, M. (1975): An Introduction to Systemic Linguistics: 1 Structure and Systems, London and Sydney, Batsford.

Berry, M. (1989): 'Thematic options and success in writing,' In Christopher S. Butler, et al. (eds.) Language \& Literature - Theory \& Practice: A Tribute to Walter Grauberg, Nottingham: Nottingham University.

Carter, R. (1987): Vocabulary: Applied linguistic perspectives, London, Unwin Hyman.

CHANG, N.-F. (張南峰) (1996): 〈雞蛋裏挑骨頭 - 評《傲慢與偏見》的兩種譯本) ('Is there a bone in the egg? - A comment on two Chinese versions of Pride and Prejudice'), In Jane C.C. Lai (ed.) 《翻譯訕賞》('Appreciation of Translations'), Hong Kong, Shangwu, 121-129.

Chen, D. (陳定安) (1985): English and Chinese: A Comparative Study, Hong Kong, Shangwu.

Chen, X. (陳獻忠) (2001): 〈如何培養䧽譯自我偵錯能力〉('How to cultivate students' ability to detect errors in their own translations'). Conference paper presented at The 5th Symposium on the Teaching of Translation and Interpreting, Taipei: National Taiwan Normal U., January.

Coulthard, M. (1985): An Introduction to Discourse Analysis, London and New York, Longman.

FAwCETT, P. 1997. Translation and Language: Linguistic Theories Explained, Manchester, UK, St. Jerome.

Fowler, R. (1996): Linguistic Criticism, Oxford and New York, Oxford UP.

Grice, H.P. 1975. 'Logic and conversation.' In P. Cole and J. Morgan (eds.) Syntax and Semantics, III: Speech Acts, New York, Academic Press, p. 41-58.

Gutknecht, C. and L. J. Rölle (1996): Translating by Factors, Albany, State U. of New York Press. Halliday, M.A.K. (1985): An Introduction to Functional Grammar, London, Arnold.

Halliday, M.A.K. (2001): Unpublished seminar handout. 'Systems and grammaticalization in Chinese and English; metafunctional analysis of issues such as Subject and Theme.' Hong Kong, City University of Hong Kong. 
Halliday, M.A.K. and R. Hasan (1976): Cohesion in English, Harlow, Longman.

Hatım, B. (1999): 'Implications of research into translator invisibility', Target 11-2, p. 201-22.

Hatim, B. and I. Mason (1990): Discourse and the Translator, London and New York, Longman. IshikaWA, M. (1991): 'Iconicity in discourse: the case of repetition,' Text 11-4, 553-580.

Lambrecht, K. (1994): Information Structure and Sentence Form: Topic, focus, and the mental representation of discourse referents, Cambridge, New York and Melbourne, Cambridge UP.

Leech, G. N. and M. H. Short (1981): Style in Fiction: A Linguistic Introduction to English Fictional Prose, London and New York, Longman.

Li, C. N. and S. A. Thompson (1981): Mandarin Chinese: A Functional Reference Grammar, Berkeley, Los Angeles and London, University of California Press.

LI, S. (李素)(tr.) (1945): 《䣖傲與偏見》('Pride and Prejudice'), Hong Kong, Sihai.

Linde, C. and W. Labov (1975): 'Spatial networks as a site for the study of language and thought,' Language 51, p. 924-939.

McCarthy, M. (1991): Discourse Analysis for Language Teachers, Cambridge, Cambridge University Press.

McCarthy, M. (1994): “'It," "this" and "that"' In Coulthard, R.M. (ed.) Advances in Written Text Analysis, London and New York, Routledge, p. 266-275.

Nash, W. (1980): Designs in Prose: A Study of Compositional Problems and Methods, London and New York, Longman.

Nash, W. (1992): An Uncommon Tongue - The Uses and Resources of English, London, Routledge.

Neubert, A. and G. M. Shreve (1992): Translation as Text, Kent, Ohio and London, England, Kent State UP.

Newmark, P. (1988): A Textbook of Translation, New York, London, Prentice Hall.

Nord, C. (1991): Text Analysis in Translation: Theory, Methodology, and Didactic Application of a Model for Translation-Oriented Text Analysis, Amsterdam, Rodopi.

Nord, C. (1997): Translation as a Purposeful Activity, Manchester, UK, St. Jerome.

Sun, Z. (孫致禮) (1997): 〈關於我國翻譯理論建設的幾點思考〉 ('My reflections on establishing China's translation theory'). In Chinese Translators Journal 2, p. 10-12.

Tannen, D. (1989): Talking Voices: Repetition, Dialogue, and Imagery in Conversational Discourse, Cambridge, Cambridge U. Press.

Thomas, J. (1995): Meaning in Interaction: An introduction to pragmatics, London and New York, Longman.

WANG, K. (王科一) (tr.) (1980): 《傲慢與偏見》('Pride and Prejudice'), Shanghai, Yiwen,

Xu, Y. (1987): 'A study of referential functions of demonstratives in Chinese discourse,' In Journal of Chinese Linguistics 15-1, p. 132-151.

Zhu, C. (1996a): 'Climb up and look down: on sentences as the key functional UT (Unit of Translation) in text translation.' In Proceedings of the 14th World Congress of the Fédération Internationale des Traducteurs (FIT), Vol. 1, Melbourne, AUSIT, p. 322-343.

Zhu, C. (1996b): 'Translation of modifications: about information, intention and effect,' Target 8 2. p. 301-324.

ZHu, C. (1996c.): 'From functional grammar and speech-act theory to Structure of Meaning: a three-dimensional perspective on translating,' Meta 41-3, p. 338-355.

Zhu, C. (1999): 'UT once more: the sentence as the key functional Unit of Translation,' Meta 443, p. 429-447.

Zhu, C. Forthcoming. 'Translation: theories, practice and teaching.' In Eva Hung (ed.) Teaching Translation and Interpreting: Building Bridges. Amsterdam/Philadelphia: John Benjamins. 